\title{
FORMAÇÃO CONTINUADA DE PROFESSORES: UM ESTUDO EXPLORATÓRIO NO RIO GRANDE DO SUL
}

\author{
CONTINUED TEACHER TRAINING: AN EXPLORATORY STUDY \\ IN RIO GRANDE DO SUL
} FORMACIÓN PROFESIONAL ACTUAL: UN ESTUDIO
EXPLORATORIO DE UNO EN RIO GRANDE DO SUL

\author{
MARCELO FonseCA ViVian ${ }^{\mathrm{I}}$ \\ MARA Elisângela JaPPE GoI ${ }^{\mathrm{I}}$ \\ ${ }^{\text {I } U n i v e r s i d a d e ~ F e d e r a l ~ d o ~ P a m p a ~(U N I P A M P A), ~ C a c ̧ a p a v a ~ d o ~ S u l / R S-B r a s i l ~}$
}

\begin{abstract}
Resumo Considerando que educação e formação docente são atividades que possuem relações de dependências e que a valorização docente é um dos fatores para a solução de problemas na educação, percebe-se a relevância da qualidade da formação inicial e continuada de professores. Nesse sentido, destaca-se a importância de pesquisas acerca das iniciativas de formação continuada como forma de conhecer tais ações, assim como de fornecer subsídios para formações futuras. Sabendo-se da relevância do Estado na promoção de iniciativas de formação continuada, apresenta-se neste trabalho dados de uma pesquisa realizada em quatro Coordenadorias Regionais de Educação (CRE) do Estado do Rio Grande do Sul, sendo que estas coordenadorias atendem as demandas das escolas Estaduais. Esta pesquisa é de cunho qualitativo e quantitativo, tendo como instrumento de pesquisa utilizou-se um questionário, composto por questões de múltipla escolha e descritivas, abordando a temática "formação continuada de professores". As questões visam obter informações sobre o desenvolvimento das ações de formação continuada, não envolvendo aspectos pessoais. A partir da pesquisa foi possível observar aspectos referentes às características gerais de ações de formação continuada, assuntos abordados e existência de formação específica para professores de cada área do conhecimento.
\end{abstract}

Palavras-chave: Formação continuada de Professores; Ciências da Natureza; EduCaÇÃo Básica; CoOrdenadorias Regionais de EducaÇão.

ABSTRact Considering that teacher education and training are activities that show dependency relationships, and that teacher evaluation is one of the factors in solving problems in education, we can see the relevance of the quality of initial and continuing teacher education. College. In this sense, the importance of research on lifelong learning initiatives 
is highlighted, as a way to learn about these actions, in addition to providing subsidies for future training. Knowing the relevance of the State in promoting permanent education actions, this work presents data from a survey conducted in four Regional Education Coordinators (CRE) in the State of Rio Grande do Sul, and these coordinators meet the demands of Public Schools. This research is qualitative and quantitative, using a questionnaire as a research tool, consisting of multiple choice and descriptive questions, which addresses the theme "continuing teacher education". The questions aim to obtain information about the development of permanent education actions, not involving personal aspects. From the research, it was possible to observe aspects related to the general characteristics of continuing education actions, the themes addressed and the existence of specific training for teachers in each area of knowledge.

Keywords: Continuing teacher training. Science of Nature. Basic eduCation. ReGIONAL EDUCATION COORDINATION.

RESUMEN Considerando que la formación y formación docente son actividades que muestran relaciones de dependencia y que la evaluación docente es uno de los factores en la resolución de problemas en la educación, se percibe la relevancia de la calidad de la formación inicial y continua docente. Universidad. En este sentido, se destaca la importancia de la investigación sobre iniciativas de educación permanente, como una forma de conocer estas acciones, además de otorgar subvenciones para futuras formaciones. Conociendo la relevancia del Estado en promover acciones de educación permanente, este trabajo presenta datos de una encuesta realizada en cuatro Coordinadores Regionales de Educación (CRE) en el Estado de Rio Grande do Sul, y estos coordinadores atienden las demandas de las Escuelas Públicas. Esta investigación es de carácter cualitativo y cuantitativo, utilizando un cuestionario como herramienta de investigación, compuesto por preguntas de opción múltiple y descriptivas, que aborda el tema "formación continua del profesorado". Las preguntas tienen como objetivo obtener información sobre el desarrollo de acciones de educación permanente, no involucrando aspectos personales. A partir de la investigación, fue posible observar aspectos relacionados con las características generales de las acciones de educación continua, la temática abordada y la existencia de formación específica para docentes en cada área de conocimiento.

Palabras Clave: Formación continua del profesorado; CiénCias de la naturaleza; EdUCACión Básica; CoORdinadores Regionales de EdUCACión.

\section{INTRODUÇÃo}

A escola configura-se como uma das instituições responsáveis pelos processos de ensino e de aprendizagem dos conhecimentos científicos, históricos, linguísticos e matemáticos, social e historicamente produzidos, tendo como um dos participantes deste processo o professor. Porém, sendo o professor um profissional cuja atuação ocorre no contexto da sala de aula, com suas características, problemas e peculiaridades, seus conhecimentos não podem estarem restritos somente aos conceitos a serem ensinados e ao como ensiná-los, 
mas também como atuar neste contexto complexo e singular. Nesse sentido, Silva (2016) discorre que a formação de professores deve superar a aquisição de conhecimentos científicos e de métodos e técnicas de ensino, abrangendo a consciência da função social de ensinar e da recíproca influência entre a ação docente sobre a comunidade em que ela ocorre.

Destaca-se, assim, a importância da formação inicial e continuada na constituição docente. Em relação à formação inicial, Cunha $(2013,2014)$ cita que esta consiste na em processos institucionais de formação que produzem a licença para o exercício e reconhecimento legal e público, mas sendo uma etapa da trajetória formativa não totalmente suficiente para as exigências deste campo profissional. No que tange a formação continuada, Cunha $(2013,2014)$ conceitua esta etapa formativa como iniciativas realizadas no período da atuação profissional docente, podendo ter diferentes formatos e duração.

Segundo Imbernón (2010), na atualidade existem diversos elementos que podem influenciar a educação escolar e, por consequência, a formação docente. São elementos destacados pelo autor: a) aumento e transformação nas formas da comunidade social, do conhecimento científico e dos resultados do pensamento, cultura e artes; b) evolução da sociedade em suas estruturas materiais, institucionais e de formas de convivência, propiciando novas formas de viver, pensar, sentir e agir; c) evolução nos meios de comunicação em massa, promovendo crise na transmissão de conhecimento de formas tradicionais e, por consequência, nas instituições destinadas a este fim; d) estabelecimento de modelos relacionais e participativos na prática da educação, em que o contexto pode apresentar maior influência que a educação regrada; e) existência de uma sociedade multicultural e multilíngue, em que é fundamental viver em igualdade e conviver na diversidade; f) compartilhamento da transmissão do conhecimento pelo professor com diversas instâncias socializadoras, como televisão, meios de comunicação em geral e redes informáticas; g) a relevância adquirida pela contribuição sociocultural na educação, tais como comunicação, trabalhos em grupo, produção conjunta de projetos, tomada democráticas de decisões (IMBERNÓN, 2010). Assim, percebem-se características que podem impactar na organização e nos objetivos da educação escolar, acarretando novas demandas e exigências na atuação docente, o que, por sua vez, repercute nos processos de formação de professores, tanto na inicial quanto na continuada.

Assim, o aspecto do como se ensina relaciona-se com o professor, sendo essencial para este processo a qualidade de sua formação inicial, assim como a complementação propiciada pela formação continuada. Logo, um dos objetivos das iniciativas de formação continuada é a constante atualização dos professores frente às inovações e às mudanças no campo da educação e do ensino (GENTILINI; SCARLATTO, 2015). Gentilini e Scarlatto (2015) discorrem que inovações muitas vezes relacionam-se a ações deliberadas e planejadas, sendo controladas por instituições educacionais e organizações escolares, enquanto mudanças nem sempre são deliberadas e percebidas imediatamente, mas podem impactar a médio e longo prazo sobre instituições e organizações. No que tange as mudanças na educação Gentilini e Scarlatto (2015) destacam: 
educacionais e impondo novas exigências em termos de competências, atitudes e habilidades que se pretendem obter com a educação. Podem ser motivadas pelos novos problemas que se colocam à sociedade ou motivadas pela ampliação das fronteiras do conhecimento no campo educacional, inclusive, como respostas a esses problemas. É importante lembrar, entretanto, que tanto inovações quanto mudanças não trazem, em si, um elemento positivo ou de progresso: podendo causar tanto avanços quanto retrocessos (GENTILINI; SCARLATTO, 2015, p. 28).

Outro fato a ser destacado consiste na correlação entre resolução de problemas da educação e valorização dos professores, como é citado nos Parâmetros Curriculares Nacionais $(\mathrm{PCN})$ para o Ensino Fundamental:

A garantia do acesso e da permanência dependem da solução de problemas variados dentre os quais se destacam os ligados à repetência, que produz a distorção idade/série e/ou a evasão. Desse modo, as ações referentes à oferta de vagas são ainda necessárias, mas as políticas educacionais não podem ficar restritas a elas. É preciso desenvolver políticas de valorização dos professores, visando à melhoria das condições de trabalho e de salário, assim como é igualmente importante investir na sua qualificação, capacitando-os para que possam oferecer um ensino de qualidade, ou seja, um ensino mais relevante e significativo para os alunos (BRASIL, 1998, p. 38).

Percebe-se a importância da formação de professores, sobretudo a formação continuada, frente à evolução social, científica e tecnológica, as quais tornam o processo de educação escolar passível de modificações, assim como a relevância de sua atuação na melhoria da qualidade da educação.

Considerando a importância da formação continuada para a prática docente e para educação escolar, desenvolveu-se o projeto de pesquisa intitulado Formação Continuada de Professores de Ciências da Natureza, no âmbito da Universidade Federal do Pampa (UNIPAMPA), campus Caçapava do Sul. O objetivo principal deste projeto compreende a realização de um estudo sistemático sobre como as Coordenadorias Regionais de Educação (CRE) do Estado do Rio Grande do Sul implementam sua jornada de formação continuada. A partir deste projeto motivou-se a realização deste trabalho, o qual tem como objetivo caracterizar aspectos referentes ao desenvolvimento da formação continuada de professores em quatro CREs, especialmente no que tange as características gerais das ações de formação continuada (duração, período de realização e formas de oferta), os principais assuntos abordados e a existência de ações de formação especificas para a área das Ciências da Natureza.

\section{REFERENCIAL TEÓRICO}

De acordo com Saviani (2009), um dos primeiros indícios de preocupação com a formação de professores no Brasil foi em 1827, com a Lei das Escolas de Primeiras Letras, a qual definia que os professores deveriam ser "treinados", embora que por próprias custas. A responsabilidade do Estado na formação de docente surge em 1834, em que as províncias 
foram responsabilizadas pela instrução primária e pela formação de professores em escolas normais. Na década de 1930 organizaram-se os cursos de pedagogia e licenciaturas, em formato conhecido como $3+1$, no qual os três primeiros anos se dedicavam ao estudo de disciplinas específicas relacionadas aos conceitos a serem ensinados, enquanto no último se destinava à formação didática. Assim, eram formados os professores para exercer a docência em Escolas Secundárias e Escolas Normais. Em Escolas Normais e Institutos de Educação eram formados os professores destinados ao ensino primário (SAVIANI, 2009; GATTI, 2010).

Gentilini e Scarlatto (2015) sinalizam que devido à reforma na educação brasileira realizada em 1971, organizou-se o ensino em $1^{\circ}$ Grau, responsável pela alfabetização e aprendizado de conteúdos básicos de disciplinas gerais, e em $2^{\circ} \mathrm{Grau}$, com a possibilidade de habilitação técnica ou profissionalizante. Esta mesma reforma incidiu sobre a formação de professores, implementando a habilitação de $2^{\circ}$ Grau para o magistério em duas modalidades, sendo uma com a duração de três anos, destinada à docência até a $4^{\mathrm{a}}$ série; e outra com duração de quatro anos, voltada para o exercício do magistério até a $6^{\mathrm{a}}$ Série do $1^{\circ}$ Grau (SAVIANI, 2009). Nesse período, as licenciaturas curtas, com duração de três anos, e licenciaturas plenas, com quatro anos de duração, destinavam-se à habilitação das quatro séries finais do primeiro grau e para o segundo grau (SAVIANI, 2009; GENTILINI; SCARLATTO, 2015). Nesse contexto, ações de requalificação dos professores pós-formação inicial consistiam em cursos padronizados, que abordavam conteúdos disciplinares fragmentados, assim como práticas modernas e eficientes de ensino, desconsiderando aspectos coletivos, integradores e interdisciplinares do trabalho pedagógico (GENTILINI; SCARLATTO, 2015).

Segundo Gatti (2010), com a Lei de Diretrizes e Bases da Educação Nacional de 1996 (LDB) é definido a obrigatoriedade de formação em nível superior para atuação também nas primeiras séries do Ensino Fundamental. A mesma autora discorre que, a partir da publicação da LDB em 1996, assim como, com as Diretrizes Curriculares Nacionais para a Formação de Professores, publicadas em 2002, e com as Diretrizes Curriculares para cada curso de licenciatura aprovadas pelo Conselho Nacional de Educação nos anos seguintes, houve orientações para uma maior integração entre formação disciplinar e formação para a docência nos cursos de licenciatura e pedagogia (GATTI, 2010).

Nota-se, assim, que a educação escolar e a formação docente são processos interligados e dependentes, que estão em constante processo de modificação de acordo com cada momento histórico e social, como exposto por Imbernón (2010).

No que tange a formação continuada de professores, Gatti (2008) cita a existência de inúmeras ações neste sentido no contexto brasileiro. Essa diversidade está relacionada às questões que emergem na sociedade contemporânea, aos desafios relacionados ao currículo e às mudanças no ensino, à maior abrangência da educação com elevação no número de crianças e jovens atendidos, aos desafios do cotidiano escolar, assim como a necessidade de atualização e renovação (GATTI, 2008).

Ainda em relação à formação continuada, a Resolução CNE/CP n ${ }^{\circ} 1$ de 2020 (BRASIL, 2020), que dispõe sobre as Diretrizes Curriculares Nacionais para a Formação Continuada de Professores da Educação Básica, propõe que cursos e ações de formação conti- 
nuada, mediante atividades formativas diversas, presenciais, a distância, semipresenciais, de forma híbrida, ou por outras estratégias não presenciais, podem ser ofertadas por Instituições de Ensino Superior, organizações especializadas ou órgãos formativos das redes de ensino, abrangendo cursos de atualização, cursos e programas de extensão, cursos de aperfeiçoamento, Cursos de pós-graduação lato sensu de especialização, cursos e programas de mestrado acadêmico e profissional e de doutorado. A possibilidade de realização de formação continuada de professores à distância também é incluída na LDB (BRASIL, 1996), por meio da Lei no 12.056 de 2009, na qual é destacado que "a formação continuada e a capacitação dos profissionais de magistério poderão utilizar recursos e tecnologias de educação à distância" (BRASIL, 2009). Assim, percebe-se a possibilidade de uma diversidade em ações de formação continuada. Tal diversidade perpassa as formas de oferta, sejam presencias ou não presencias, assim como as modalidades, desde cursos ou pós-graduações.

No que tange às ações oficiais de formação continuada, Echeveria e Belisário (2008) descrevem que tais ações, em geral, consistem em projetos que oferecem cursos de atualização, cursos presenciais promovidos em período de férias ou mesmo em períodos de aula, ou ainda programas de estudo oferecidos à distância. Nery e Maldaner (2012) citam que o modelo de formação continuada oferecido por secretarias estaduais de educação muitas vezes consiste em ações de capacitação, tendo como responsáveis profissionais normalmente pertencentes a instituições de ensino superior, que possuem um saber a ser ensinado aos professores que atuam em sala de aula. Embora considerando que ações de formação continuada como cursos rápidos, simpósios, encontros e palestras apresentem limitações, Nery e Maldaner (2012) argumentam do potencial formativo destas ações, uma vez que:

\begin{abstract}
Além de proporcionar o contato dos professores, com algum pesquisador dos assuntos da educação geralmente, permite ao formador de novos professores, se for o caso, um contato com a realidade escolar e sua problemática em seu trabalho na licenciatura, e, ao mesmo tempo, indica parâmetros para a melhora do trabalho nas escolas (NERY; MALDANER, 2012, p.124).
\end{abstract}

Assim, pode-se perceber que mesmo ações de formação continuada de menor duração possuem seu aspecto formativo, em especial na interação entre professores da Educação Básica e formador professor das licenciaturas. Subentende-se que nesta interação ocorrida durante o curso de formação continuada o professor da Educação Básica pode se apropriar de aspectos abordados pelo formador, sejam epistemológicos, metodológicos, pedagógicos, psicológicos, de gestão escolar, entre outros, enquanto o formador tem a oportunidade de conhecer e reconhecer aspectos do contexto escolar, os quais diversas vezes são vivenciados somente pelos sujeitos que estão inseridos efetivamente em escolas de Educação Básica.

Ações de formação continuada de professores oficiais em âmbito de Estados e Municípios brasileiros foi tema de estudo realizado por Davis et al. (2011), cujo objetivo consistia na verificação acerca do desenvolvimento dessa etapa da formativa docente, sendo a pesquisa realizada em Secretárias de Educação. Os autores destacam entre os 
aspectos observados um consenso acerca da visão sobre a formação continuada relativo à "importância conferida aos professores e à sua formação na melhoria da qualidade do ensino; o entendimento de que a formação é o eixo articulador das intervenções na escola; a oferta de FCP pautada pelas avaliações de sistema e a necessidade de promover práticas formativas sistemáticas" (DAVIS et al., 2011, p. 835). Segundo Davis et al. (2011), esse consenso pode ter relações com políticas nacionais e internacionais, as quais promovem as secretárias de educação um olhar mais voltado aos docentes, em que ações de formação continuada assumem relevância estratégica nas redes de ensino.

Dessa forma, Davis et al. (2011) destacam que as secretarias de educação consideram a formação continuada como uma das condições para a melhoria da educação. Outro aspecto citado é compreensão de que formações continuadas não podem se restringir a suprir falhas da formação inicial, mas sim propiciar o desenvolvimento profissional e favorecer a gestão escolar (DAVIS et al., 2011). Ainda em relação às ações formativas, os mesmos autores evidenciam a ocorrência de um aprimoramento no desenvolvimento das ações de formação continuada, visto que as secretárias visam atender as necessidades docentes, evitando ações formativas pontuais, isoladas ou de curta duração (DAVIS et al., 2011).

Em relação às práticas formativas, Davis et al. (2011) citam que diversas secretárias desenvolvem cursos voltados ao aprimoramento de saberes e práticas docentes, assim como a coexistência de diversas modalidades de formação continuada apresentada especialmente em secretárias de cidades de maior porte. Os autores destacam que as principais diferenças entre as políticas adotadas pelas secretárias consistem nas várias modalidades oferecidas e o foco em trabalho individual e coletivo. Em perspectivas individualizadas consistem em sanar dificuldades de formação em relação à escola atual e práticas pedagógicas, assim como divulgar mudanças pedagógicas ou implementar programas e políticas, podendo abranger cursos de curta ou longa duração; oficinas; ações que consideram o ciclo de vida e o desenvolvimento profissional. Em perspectivas colaborativas a escola é considerada lócus para a formação continuada, e abrangem grupos de estudos; produção coletiva de matérias; processos de planejamento, implementação e avaliação de ações; elaboração de projetos pedagógicos; formação de redes virtuais de colaboração e apoio profissional entre comunidades escolares e sistemas educacionais (DAVIS et al., 2011).

Percebe-se, a partir do exposto, que ações de formação continuada no contexto brasileiro podem apresentar características diversificadas, sendo estas relacionadas à duração da ação, assim como aos objetivos e aos formatos com aspectos individualizados ou coletivos. Verifica-se também a importância atribuída às ações de formação continuada para o desenvolvimento profissional docente, fato que apresenta implicações à prática pedagógica e melhorias na qualidade da educação.

Sobre a formação continuada, em um contexto geral, Schnetzler (2002) discorre que se constituem como condições essenciais para sua realização a formação de grupos de professores, com reuniões periódicas, promovendo a discussão sobre problemas reais da prática docente, podendo utilizar o auxílio de um professor universitário. E, ao realizar essa formação, preferencialmente na escola, pode ser promovida a cultura de desenvolvimento profissional do professor em coletivo, por meio da pesquisa do próprio fazer docente, pelo compartilhamento com os colegas docentes das ações de 
investigação e dos resultados obtidos, assim como pela reflexão sobre o contexto em que ocorre seu trabalho (SCHNETZLER, 2002).

Maldaner (1999) recomenda, como recurso na formação inicial e continuada de professores de Química, que os docentes se tornem pesquisadores sobre a própria prática, estando atentos sobre as ações praticadas, produzindo novas ações. A partir dessas considerações, o autor vislumbra que os encontros de professores se configurariam em espaços de discussões dos conhecimentos por eles produzidos, em suas próprias salas de aula, na interação com os alunos e seus pares na escola. Percebe-se, assim, que a pesquisa se configura como o processo formativo.

Mesmo de forma singular, Schnetzler (2002) e Maldaner (1999) sugerem em seus trabalhos elementos semelhantes para a formação continuada, tais como a investigação ou pesquisa sobre a prática, a reflexão que gera uma análise sobre a ação e o trabalho coletivo na produção de novos significados. Esses elementos alinham-se com a perspectiva de formação continuada discutida por Imbernón (2010), baseada em uma formação coletiva prevalecente à individual, priorizando a reflexão sobre a prática e situações problemáticas, com estrutura organizativa que permita a comunicação e trocas de experiências com o objetivo de compreender, interpretar e intervir sobre a prática.

Nessa mesma linha, Tardif (2010) argumenta que os docentes possuem um saber plural, constituído por saberes da formação profissional (pedagógicos e das Ciências da educação) e saberes disciplinares (correspondentes aos campos de conhecimento, organizados nas disciplinas), ambos provenientes da formação inicial ou continuada, também por saberes curriculares (relativo aos programas de ensino das instituições escolares) e por saberes experienciais (relativo aos saberes provenientes e validados pela experiência do professor no contexto escolar), sendo os dois últimos saberes provenientes do ambiente escolar. $\mathrm{O}$ autor destaca que os saberes experienciais são produzidos pelo professor no contexto da prática escolar, com seus limitantes, na interação com alunos, assim como com seus pares.

Dessa forma, percebe-se a importância do contexto da escola e das interações dos sujeitos dele participantes no processo de desenvolvimento e constituição da identidade do professor. À vista disso, Rosa (2004) defende a possibilidade de a escola ser considerada como um espaço de construção de conhecimentos pedagógicos e a prática do professor de Ciências como um conjunto de ações balizadas em saberes válidos, os quais necessitam ser considerados durante os programas de formação continuada.

A partir do exposto, diversos aspectos são sinalizados como importantes para o processo de formação continuada, tais como: reflexão sobre a prática, o trabalho e contexto coletivo (MALDANER, 1999; SCHNETZLER, 2002, IMBERNÓN, 2010), os saberes provenientes da prática, a escola e seu contexto (TARDIF, 2010; ROSA, 2004;) e a interação entre professores e agentes externos (SCHNETZLER, 2002).

Tendo por base os argumentos supracitados no decorrer do texto e considerando a importância do Estado na promoção de iniciativas de formação continuada de professores, apresentam-se neste trabalho os dados produzidos em quatro CREs do Estado do Rio Grande do Sul, que atendem as escolas Estaduais, objetivando caracterizar aspectos referentes ao desenvolvimento da formação continuada de professores. 


\section{Metodologia da PeSQuisa}

A pesquisa apresenta caráter qualitativo (LÜKDE; ANDRÉ, 1986) e quantitativo, por utilizar de dados numéricos (LAKATOS; MARCONI, 2017). O objetivo consiste em realizar um estudo exploratório acerca das ações de formação continuada de professores desenvolvidas por CREs, visando identificar características quanto à oferta, assuntos abordados e existência de formação específica para cada área do conhecimento. O contexto da pesquisa compreendeu quatro CREs, representadas pelas letras A, B, C e D. Estas coordenadorias atendem 47 municípios abrangendo as escolas Estaduais.

Utilizou-se como instrumento de pesquisa um questionário, apresentado no Quadro 1, composto por questões de múltipla escolha e descritivas, abordando a temática: formação continuada de professores. As questões visam obter informações sobre o desenvolvimento das ações de formação continuada, não envolvendo aspectos pessoais. Nessa etapa da pesquisa empregou-se como recurso plataforma digital destinada à criação de formulários, com envio e recebimento de respostas. Este questionário foi enviado para as CREs por meio de e-mail.

Quadro 1 - Questões presentes no formulário1.

1) Existem formações continuadas para professores realizadas pela Coordenadoria Regional de Educação?

( ) $\operatorname{Sim}$

( ) Não

2) Como ocorre a formação continuada oferecida pela Coordenadoria Regional de Educação, quanto às modalidades:

( ) Cursos de atualização

( ) Atividades de extensão

( ) Cursos de aperfeiçoamento

3) Como ocorre a formação continuada oferecida pela Coordenadoria Regional de Educação, quanto à oferta:

( ) Presencial

( ) Semipresencial

( ) À distância

Questões elaboradas pelos participantes do "Projeto de Pesquisa Formação Continuada de Professores de Ciências da Natureza". 
4) Como ocorre a formação continuada oferecida pela Coordenadoria Regional de Educação, quanto à duração:

( ) Menos de 20 horas

( ) De 20 a 40 horas

( ) De 40 a 60 horas

( ) Mais de 60 horas

5) Como ocorre a formação continuada oferecida pela Coordenadoria Regional de Educação, quanto ao período em que ocorrem:

( ) Férias escolares de inverno

( ) Férias escolares de verão

( ) Concomitante ao ano letivo

6) Como é realizada a divulgação das atividades de formação continuada? Como é a participação dos professores?

7) Quais os principais aspectos ou assuntos abordados durante as formações continuadas?

8) De que forma esses assuntos são levantados para que possam ser trabalhados em ação de formação?

9) Existe formação específica para cada área do conhecimento?

( ) $\operatorname{Sim}$

( ) Não

10) Se existe, quais os principais aspectos e assuntos abordados nas formações da área de Ciências da Natureza?

Fonte: Projeto de Pesquisa Formação Continuada de Professores de Ciências da Natureza.

A partir dos dados obtidos emergiram categorias de análise, que segundo Bardin (2011), resultam a partir do processo de desmembramento do texto em unidades de acordo com o critério de reagrupamento analógico. Neste trabalho apresentam-se a discussão acerca das seguintes categorias: i) características da formação continuada de professores; ii) assuntos abordados nas formações continuadas; iii) formação continuada específica para professores de Ciências da Natureza.

\section{RESULTADOS E DiSCUSSÕES}

Por meio dos dados obtidos organizaram-se categorias de análise ${ }^{2}$ relativas às características da formação continuada de professores, aos assuntos abordados nas formações

2 As categorias "características da formação continuada de professores" e "assuntos abordados nas formações continuadas" derivam das categorias presentes em trabalho intitulado "Formação continuada de professores: um estudo em Coordenadorias Regionais de Educação do RS", de autoria de MENEZES, SILVA, VIVIAN, BORGES; GOI. 
continuadas e à formação continuada específica para professores de Ciências da Natureza. A seguir, apresenta-se a discussão de cada categoria.

\section{Características da formação continuada de professores}

Nesta categoria observam-se características básicas dos processos de formação continuada, tais como oferta, carga horária e período do ano em que são desenvolvidas as formações. Por conseguinte, procura-se explorar aspectos gerais relativos à organização das ações de formação continuada. Os dados quantitativos desta categoria estão expostos no Quadro 2:

Quadro 2 - Características gerais de formações continuadas de professores.

\begin{tabular}{|c|c|c|}
\hline \multicolumn{2}{|c|}{ Características gerais } & Número de respostas \\
\hline \multirow{4}{*}{ Modalidades } & Cursos de atualização & 1 \\
\cline { 2 - 3 } & Atividades de extensão & 1 \\
\cline { 2 - 3 } & Cursos de aperfeiçoamento & 2 \\
\hline \multirow{3}{*}{ Oferta } & Presencial & 1 \\
\cline { 2 - 3 } & Semipresencial & 3 \\
\cline { 2 - 3 } & À distância & 0 \\
\hline \multirow{4}{*}{ Carga horária } & Menos de 20 horas & 1 \\
\cline { 2 - 3 } & De 20 a 40 horas & 1 \\
\cline { 2 - 3 } & De 40 a 60 horas & 2 \\
\cline { 2 - 3 } & Mais de 60 horas & 0 \\
\hline \multirow{3}{*}{ Período } & Férias escolares de inverno & 0 \\
\cline { 2 - 3 } & Férias escolares de verão & 0 \\
\cline { 2 - 3 } & Concomitante ao ano letivo & 4 \\
\hline
\end{tabular}

Fonte: Os autores.

Analisando os dados expostos no Quadro 02, destaca-se que a modalidade prevalecente são cursos de aperfeiçoamento (2 CREs). Quanto à carga horária, apesar da heterogeneidade observada nos dados, prevaleceu a opção que comportava atividades de 40 a 60 horas (2 CREs). Uma maior consonância é observada quanto à prevalência da oferta semipresencial (3 CREs), assim como a concomitância ao ano letivo (4 CREs). Essa última característica corrobora com o exposto por Echeveria e Belisário (2008), que citam como uma das características de determinados cursos de formação continuada consiste na oferta concomitante ao ano letivo.

Porém, essa análise proporciona vislumbrar uma tendência para ações de formação continuada, perpassando cursos de aperfeiçoamento, carga horária de 40 a 60 horas, atividades semipresenciais, assim como a realização de formação continuada juntamente ao ano letivo. Uma percepção mais detalhada pode ser obtida por meio da análise das ações de formação continuada desenvolvida por cada CRE participante da pesquisa, como exposto no Quadro 3: 
Quadro 3 - Características das formações continuadas nas CREs.

\begin{tabular}{|c|c|c|c|c|}
\hline \multirow{2}{*}{ CRE } & \multicolumn{4}{|c|}{ Características gerais } \\
\cline { 2 - 5 } & Modalidades & Oferta & Duração & Período \\
\hline A & $\begin{array}{c}\text { Cursos de } \\
\text { aperfeiçoamento }\end{array}$ & Semipresencial & De 40 a 60 horas & $\begin{array}{c}\text { Concomitante ao } \\
\text { ano letivo }\end{array}$ \\
\hline B & $\begin{array}{c}\text { Cursos de } \\
\text { aperfeiçoamento }\end{array}$ & Semipresencial & De 40 a 60 horas & $\begin{array}{c}\text { Concomitante ao } \\
\text { ano letivo }\end{array}$ \\
\hline C & $\begin{array}{c}\text { Cursos de } \\
\text { atualização }\end{array}$ & Presencial & Menos de 20 horas & $\begin{array}{c}\text { Concomitante ao } \\
\text { ano letivo }\end{array}$ \\
\hline D & $\begin{array}{c}\text { Atividades de } \\
\text { extensão }\end{array}$ & Semipresencial & De 20 a 40 horas & $\begin{array}{c}\text { Concomitante ao } \\
\text { ano letivo }\end{array}$ \\
\hline
\end{tabular}

Fonte: Os autores.

Por meio dos dados expostos no Quadro 03, pode-se observar que cursos de atualização promovidos pela CRE C se realizaram de forma presencial, sendo esta ação a que apresenta a menor carga horária verificada, inferior a 20 horas. Segundo Nery e Maldaner (2012), atividades de curta duração muitas vezes são utilizadas por Secretarias de Educação. Esses mesmos autores indicam que as ações de curta duração apresentam seu potencial formativo, seja pela aproximação dos professores participantes com novos assuntos ou pelo contato do formador com realidades da Educação Básica.

Atividades de extensão promovidas pela CRE D apresentam características distintas a cursos de atualização, consistindo em ação com maior carga horária, especificamente de 20 a 40 horas, e oferta semipresencial. Todavia, as ações de formação continuada que possuem maior carga horária consistem nos cursos de aperfeiçoamento promovidos pelas CREs A e $\mathrm{B}$, os quais apresentam também linearidade quanto à oferta semipresencial.

Dessa forma, evidencia-se uma tendência de desenvolvimento de formações de maior carga horária pelas CREs. Este fato corrobora com considerações de Davis et al. (2011) em pesquisa sobre formação continuada de professores realizada por Secretarias de Educação brasileiras. Esses autores verificaram nas ações de formação continuada realizadas pelas Secretarias de Educação o empenho em atender as necessidades dos docentes, evitando atividades isoladas, pontuais e/ou de curta duração (DAVIS, et al., 2011).

\section{ASSUNTOS ABORDADOS NAS FORMAÇÕES CONTINUADAS}

De acordo com os dados obtidos verificou-se a abordagem de diversos assuntos nas ações de formação continuada, como exposto no Quadro 4:

Quadro 4 - Assuntos abordados em formações continuadas nas CREs.

\begin{tabular}{|c|c|}
\hline CRE & Assuntos abordados \\
\hline $\mathbf{A}$ & $\begin{array}{l}\text { Sustentabilidade, meio ambiente, avaliação, planejamentos, } \\
\text { metodologias ativas, ensino híbrido }\end{array}$ \\
\hline B & Metodologia de projetos \\
\hline $\mathbf{C}$ & $\begin{array}{l}\text { Sustentabilidade, Educação ambiental (como tema transversal em tratamento } \\
\text { interdisciplinar), assuntos específicos (feira de ciências ou datas comemorativas) }\end{array}$ \\
\hline D & $\begin{array}{c}\text { Atualizações para o Ensino Médio, metodologias para o ciclo } \\
\text { de alfabetização, metodologia ativas }\end{array}$ \\
\hline
\end{tabular}

Fonte: Os autores. 
Assuntos como sustentabilidade, educação ambiental e meio ambiente estão presentes nas formações continuadas de duas CREs (A e C), fato que evidencia a discussão de questões ambientais. A abordagem destas temáticas na Educação Básica está presente em diversos documentos oficiais, tais como os PCN e Base Nacional Comum Curricular.

De acordo com os PCN (BRASIL, 1998), integram-se à proposta educacional, temáticas como, a ética, saúde, meio ambiente, pluralidade cultural, orientação sexual, trabalho e consumo. Essas temáticas são trabalhadas de forma integrada entre as áreas. Em relação à Base Nacional Comum Curricular (BNCC), o item vinculado à discussão da relação da base com o currículo é destacado que:

\begin{abstract}
Por fim, cabe aos sistemas e redes de ensino, assim como às escolas, em suas respectivas esferas de autonomia e competência, incorporar aos currículos e às propostas pedagógicas a abordagem de temas contemporâneos que afetam a vida humana em escala local, regional e global, preferencialmente de forma transversal e integradora (BRASIL, 2017, p. 19).
\end{abstract}

Tem-se, então, a possibilidade de os currículos abarcarem a discussão de temáticas. Segundo a BNCC, estes temas podem ser: direitos da criança e do adolescente; educação para o trânsito; educação ambiental; educação alimentar e nutricional; respeito e valorização do idoso; educação em direitos humanos; educação das relações étnico-raciais e ensino de história e cultura afro-brasileira, africana e indígena; saúde, vida familiar e social; educação para o consumo; educação financeira e fiscal; trabalho, ciência e tecnologia; e diversidade cultural (BRASIL, 2017).

Assim, destaca-se que os assuntos educação ambiental, sustentabilidade e meio ambiente tratados nestas ações de formação continuada apresentam-se em consonância com os documentos oficiais anteriormente citados.

A relação entre os assuntos abordados em formação continuada de professores e as orientações de temáticas a serem discutidas na Educação Básica se faz necessária para o exercício docente, uma vez que novas demandas são incluídas aos professores, e estas, muitas vezes, podem não ter estado presentes na formação inicial, ou até mesmo em ações de formação continuada anteriores. Portanto, o alinhamento entre formação docente e objetivos para a educação configura-se como um imperativo educacional.

Por outro lado, não somente assuntos relacionados a questões ambientais são abordados nestas formações continuadas. Verificou-se, também assuntos relacionados diretamente à prática docente, tais como metodologias, ensino híbrido, avaliação e planejamentos.

Em relação às metodologias, percebem-se discussões variadas, envolvendo metodologias para alfabetização (CRE D), metodologias ativas (CREs A e D), assim como de projetos (CRE B). No que tange as metodologias ativas, essas consistem em estratégias cujo aluno é o foco do processo de ensino e aprendizagem, tendo como objetivo engajá-los em atividades que favoreçam seu protagonismo diante do processo de aprendizagem (VALENTE; ALMEIDA; GERALDINI, 2017). Assim, temos que:

[...] as metodologias ativas são estratégias pedagógicas para criar oportunidades de ensino nas quais os alunos passam a ter um comportamento mais ativo, envolvendo-os de modo que eles sejam mais engajados, realizando atividades 
que possam auxiliar o estabelecimento de relações com o contexto, o desenvolvimento de estratégias cognitivas e o processo de construção de conhecimento (VALENTE; ALMEIDA; GERALDINI, 2017, p. 464).

Nessa direção, Berbel (2011) cita que as metodologias ativas podem favorecer a autonomia dos discentes nos diferentes níveis de ensino, e são diversas as possibilidades neste sentido, dentre elas o estudo de caso, método de projetos, pesquisa científica e aprendizagem baseada em problemas.

Metodologia de projetos, segundo Garbelini (2001), baseia-se na solução de um problema ou de atividade proposta pelo professor ou ainda produzida pela curiosidade ou necessidades dos educandos, que se configura no ponto inicial do projeto. Assim, um projeto necessita de pesquisas e ações que visam obter um resultado. Nesse sentido, pode-se vislumbrar a metodologia de projetos como uma metodologia ativa.

Dessa maneira, destaca-se que as metodologias supracitadas visam maior participação, autonomia e protagonismo dos estudantes no processo de aprendizagem, fatores que podem contribuir para uma compreensão efetiva de conceitos e princípios, tal como no desenvolvimento de habilidades de pesquisa, análise crítica e resolução de problemas.

Um dos fatores que podem ser considerados no desenvolvimento dos currículos nas escolas, de acordo com a BNCC, é a efetivação de situações e procedimentos que motivem e engajem os alunos nas aprendizagens (BRASIL, 2017). No que tange o currículo do Ensino Médio, a LDB prevê a utilização de metodologias de ensino e de avaliação que estimulem a iniciativa dos estudantes (BRASIL, 1996). Considerando estas perspectivas, nota-se que a utilização de metodologias ativas pode contribuir para a prática docente em sala de aula, tornando-se relevante sua discussão em formação continuada de professores.

Outro aspecto presente em ações de formação continuada é o ensino híbrido. Segundo Bacich (2016), o ensino híbrido, embora sendo definido na literatura de diferentes formas, tem como característica a convergência entre o processo de aprendizagem presencial, ocorrido na sala de aula, e o modelo online de ensino, utilizando tecnologias digitais. Dessa forma, "no modelo híbrido, a ideia é que educadores e estudantes ensinem e aprendam em tempos e locais variados" (BACICH, 2016, p. 679). Logo, o ensino híbrido pode se configurar como uma possibilidade de recurso educacional proporcionada pelo avanço da tecnologia digital. Portanto, pode-se vislumbrar que sua discussão alinha-se com um dos objetivos da formação continuada citado por Gentilini e Scarlatto (2015), que consiste na atualização dos professores frente as inovações e as mudanças no campo da educação e do ensino. Semelhantemente, pode-se incluir neste contexto discussões sobre avaliação e atualizações para o Ensino Médio.

Planejamentos estão presentes nas formações continuadas. Segundo Tardiff (2010), professores possuem saberes profissionais, disciplinares, curriculares e experienciais. Assim, envolver os docentes em atividades de planejamento pode, além de mobilizar aspectos metodológicos discutidos em formação, promover a união destes com saberes do próprio docente, construído durante sua trajetória formativa e profissional. Destaca-se também que atividades de planejamento podem favorecer o protagonismo docente nas ações de formação continuada, assim como a reflexão sobre o desenvolvimento das aulas na Educação Básica, fato que corrobora com as Diretrizes Curriculares Nacionais para a Formação 
Inicial e Continuada em Nível Superior de Profissionais do Magistério para a Educação Básica (BRASIL, 2015, p. 14), em que a formação continuada deve considerar "o respeito ao protagonismo do professor e a um espaço-tempo que lhe permita refletir criticamente e aperfeiçoar sua prática".

\section{FormaÇão Continuada para professores de CiênCIAS da Natureza}

De acordo com os dados obtidos, a existência de formação específica para áreas do conhecimento esteve presente em somente nas CREs A e D, enquanto as CREs B e C não se identificou este tipo de formação.

Nas CREs que não apresentam formação continuada específica para cada área do conhecimento, percebe-se situações de tratamento interdisciplinar na CRE C, em que temáticas como educação ambiental são trabalhadas durante a formação continuada, envolvendo diferentes áreas do conhecimento, enquanto na CRE B as formações são interdisciplinares. Embora considerando que cada área do conhecimento possua suas especificidades, e assim demandas e necessidades formativas para seus professores, não se pode descartar a importância de formações interdisciplinares, uma vez que documentos legais, como BNCC e PCN sinalizam uma organização educacional por áreas do conhecimento e a relação entre as diferentes áreas e disciplinas, pois a organização do Ensino Médio em áreas do conhecimento busca favorecer a prática escolar na perspectiva da interdisciplinaridade (BRASIL, 2000) e o currículo necessita de ações de decisão de formas de organização interdisciplinar entre os componentes curriculares (BRASIL, 2017).

No que diz respeito às CREs que apresentam formações específicas para as diferentes áreas do conhecimento, buscou-se verificar os assuntos abordados nas formações da área de Ciências da Natureza. Nesse caso, percebe-se que assuntos relacionados à sustentabilidade, meio ambiente e metodologias ativas são descritos pela CRE A. Assuntos trabalhados em formação relacionados a metodologias ativas também são descritos pela CRE D. Nota-se, assim, que formações específicas para professores de Ciências da Natureza envolvem temáticas relacionadas à área, assim como metodologias.

\section{CONSIDERAÇões FINAIS}

Por meio da pesquisa realizada foi possível perceber a diversidade de organização e assuntos abordados na formação continuada desenvolvida pelas CREs. A diversidade nas ações de formação continuada também foi constatada em estudo de Davis et al. (2011) e de Menezes et al. (2017). A partir destas observações, pode-se vislumbrar a autonomia das coordenadorias no desenvolvimento das ações de formação continuada, fato que pode contribuir para o atendimento de necessidades locais.

Outro aspecto a se destacar é o alinhamento de assuntos discutidos nestas ações com documentos oficiais que versam sobre a Educação Básica, assim como abordagem de metodologias que visam práticas docentes que podem contribuir para participação ativa dos alunos em sala de aula. Nesse sentido, as formações podem oferecer subsídios que auxiliem os professores ao atendimento de indicações presentes nestes mesmos documentos oficiais. 
No que tange à formação continuada destinada a professores de Ciências da Natureza, ressalta-se a existência de formação específica em metade das CREs pesquisadas, com ênfase em assuntos como meio ambiente, sustentabilidade e metodologias ativas. Em relação às CREs que não descreveram o desenvolvimento de formação específica, assuntos como sustentabilidade, meio ambiente e educação ambiental podem favorecer discussões referentes a Ciências da Natureza, uma vez que temáticas e discussões relacionadas estão presentes nos PCN para o Ensino Fundamental, PCNEM e BNCC. Dessa forma, percebe-se que discussões acerca de temáticas podem apresentar potencialidades relacionadas às diversas áreas do conhecimento, beneficiando tanto a área quanto as relações interdisciplinares.

\section{REFERÊNCIAS}

BACICH, L. Ensino Híbrido: Proposta de formação de professores para uso integrado das tecnologias digitais nas ações de ensino e aprendizagem. IN: V Congresso Brasileiro de Informática na Educação (CBIE 2016), Anais do XXII Workshop de Informática na Escola, 2016.

BARDIN, L. Análise de conteúdo. São Paulo: Edições 70, 2011.

BRASIL. Lei ${ }^{0}$ 9.394, de 20 de dezembro de 1996 - Lei de Diretrizes e Bases de Educação Nacional. Brasília, 1996. Disponível em: $<$ http://www.planalto.gov.br/ccivil_03/ leis/L9394.htm>. Acesso em: 15 de junho de 2017.

BRASIL. Secretaria de Educação Fundamental. Parâmetros curriculares nacionais: terceiro e quarto ciclos do ensino fundamental - introdução aos parâmetros curriculares nacionais / Secretaria de Educação Fundamental. Brasília: MEC/SEF, 1998.

BRASIL. Secretaria de Educação Média e Tecnológica. Parâmetros Curriculares Nacionais Ensino Médio. Brasília, 2000.

BRASIL. Lei no 12.056, de 13 de outubro de 2009. Brasília, 2009. Disponível em: $<\underline{\text { http:// }}$ www.planalto.gov.br/ccivil_03/_Ato2007-2010/2009/Lei/L12056.htm\#art1>. Acesso em 18 de novembro de 2018.

BRASIL. Ministério da Educação. Base Nacional Comum Curricular. Brasília, 2017.

BRASIL. Ministério da Educação - Conselho Nacional de Educação - Conselho Pleno. Resolução CNE/CP n ${ }^{0}$ 1, de 27 de outubro de 2020. Brasília, 2020.

BERBEL, N. A. N. As metodologias ativas e a promoção da autonomia de estudantes Semina: Ciências Sociais e Humanas, v. 32, nº. 1, p. 25-40, 2011.

CUNHA, M.I. O tema da formação de professores: trajetórias e tendências do campo na pesquisa e na ação. Educação e Pesquisa, v. 39, nº 3, p. 609-625, 2013. 
CUNHA, M.I. Aprendizagem da docência em espaços institucionais: é possível fazer avançar o campo da formação de professores? Avaliação, v. 19, nº. 3, p. 789-802, 2014.

DAVIS, C.L.F.; NUNES, M.M.R.; ALMEIDA, P.C.A.; SILVA, A.P.F.; SOUZA, J.C. formação continuada de professores em alguns estados e municípios do Brasil. Cadernos de Pesquisa, v. 41, $n^{\circ} .144$, p. 826-849, 2011.

ECHEVERRÍA, A.R.; BELISÁRIO, C.M. Formação inicial e continuada de professores num núcleo de pesquisa em ensino de ciências. Revista Brasileira de Pesquisa em Educação em Ciências, v. 8, nº 3, 2008.

GATTI, B.A. Análise das políticas públicas para formação continuada no Brasil, na última década. Revista Brasileira de Educação, v. 13 nº. 37, p. 57-70, 2008.

GATTI, B.A. Formação de professores no Brasil: características e problemas. Educação e Sociedade, v. 31, $\mathrm{n}^{\mathrm{o}}$. 113, p. 1355-1379, 2010.

GARBELINI, V.M.P. O instrumental tecnológico para construir conhecimento por meio da Metodologia de projetos. Dissertação de mestrado apresentada na Universidade Federal de Santa Catarina -Programa de Pós-Graduação em Engenharia de Produção. Florianópolis, 2001.

GENTILINI, A.J.; SCARLATTO, E.C. Inovações no ensino e na formação continuada de professores: retrocessos, avanços e novas tendências. In: PARENTE, Cláudia da Mota Darós; VALLE, L. E. L. R.; MATTOS; M. J. V. M. A formação de professores frente às mudanças sociais. Politicas e tecnológicas. Porto Alegre: Penso, 2015.

IMBERNÓN, F. Formação continuada de professores. Porto Alegre: Artmed, 2010.

LAKATOS, E.M.; MARCONI, M.A. Metodologia científica. 7. Ed. São Paulo: Atlas, 2017.

LÜDKE, M.; ANDRÉ, M.E.D.A. Pesquisa em educação: abordagens qualitativas. São Paulo: EPU, 1986.

MALDANER; O.A. A pesquisa como perspectiva de formação continuada do professor de Química. Química Nova, v. 22, n. 2, p. 289-292, 1999.

MENEZES, P. D.; SILVA, E. R. A.; VIVIAN, M. F.; BORGES, P. B. P.; GOI, M. E. J. Formação continuada de professores: um estudo em Coordenadorias Regionais de Educação do RS. IN: IX Salão Internacional de Ensino, Pesquisa e Extensão (SIEPE), 2017.

NERY, B.K.; MALDANER, O.A. Formação continuada de professores de química na elaboração escrita de suas aulas a partir de um problema. Revista Electrónica de Enseñanza de las Ciencias, v. 11, n. 1, p. 120-144, 2012. 
ROSA, M.I.P. Investigação e ensino: articulações e possibilidades na formação de professores de Ciências. Ijuí: Unijuí, 2004.

SAVIANI, D. Formação de professores: aspectos históricos e teóricos do problema no contexto brasileiro. Revista Brasileira de Educação, v. 14, n. 40, p. 143-155, 2009.

SCHNETZLER, R.P. Concepções e alertas sobre formação continuada de professores de Química. Química Nova na Escola, n. 16, p. 15-20, 2002.

SILVA, L.H.A. Formação de professores de ciências: problemática, paradigmas e desafios para a mudança. In. BONOTO, Danusa de Lara; LEITE, Fabiane de Andrade; GÜLLICH, Roque Ismael da Costa. Movimentos Formativos: desafios para pensar a educação em Ciências e Matemática. Tubarão: Copiart, 2016.

TARDIF, M. Saberes docentes e formação profissional. 10ª ed. Petrópolis, RJ: Vozes, 2010.

VALENTE, V.A.; ALMEIDA, M.E.B.; GERALDINI, A.F.S. Metodologias ativas: das concepções às práticas em distintos níveis de ensino. Revista Diálogo Educacional, v. 17, n. 52, p. 455-478, 2017.

\section{DADOS DOS AUTORES}

\section{Marcelo Fonseca Vivian}

Licenciado em Ciências Exatas - Química pela Universidade Federal do Pampa (UNIPAMPA), Caçapava do Sul/RS-Brasil.marcelovivian@farrapo.com.br

\section{Mara Elisângela Jappe Goi}

Doutora em Educação pela Universidade Federal do Rio Grande do Sul (UFRGS). Docente da Universidade Federal do Pampa (UNIPAMPA), Caçapava do Sul/RS-Brasil.

maragoi28@gmail.com

Submetido em: 02-04-2020

Aceito em: 01-02-2021 